\title{
Cultivo de Tillandsia kautskyi E. Pereira, bromélia brasileira em risco de extinção: considerações sobre adubação foliar
}

\author{
MARIAESMERALDASOARES PAYÃO DEMATTÊ
}

\begin{abstract}
RESUMO
Foi objetivo observar o efeito de duas fontes de nutrientes (mineral e orgânica) sobre o crescimento de Tillandsia kautskyi. O experimento foi conduzido de janeiro de 2003 a maio de 2004, em Jaboticabal (SP), em telado com 70\% de interceptação da luz solar. As mudas foram cultivadas em vasos de plástico, em substrato constituído por $100 \%$ de fibra de coco. Foram comparados os seguintes tratamentos de adubação foliar a cada 30 dias, exceto nos meses de inverno: A1 = adubo NPK 147-28 + Mg, na dose de 0,5 g/L; A2 = A1 + húmus solúvel, na dose de 75 mg/L; A3 = húmus solúvel, na dose de 75 mg/L; A4 = testemunha sem adubação. As plantas do tratamento A1 obtiveram maior altura da parte aérea e maior comprimento do sistema radicular que as não-adubadas.
\end{abstract}

Palavras-chave: Bromeliaceae, nutrição mineral, conservação de espécies

\section{ABSTRACT}

Cultivation of Tillandsia kautskyi E. Pereira, an endangered Brazilian bromeliad: comments on foliar fertilization The effects of two nutrient sources (mineral and organic fertilizers) on the growth of Tillandsia kautskyi were observed. The experiment was carried out from January 2003 through May 2004, in Jaboticabal, state of São Paulo, Brazil, in a greenhouse with $70 \%$ shaded. Seedlings were planted in plastic pots, using $100 \%$ of coconut husk as the growing medium. The following treatments of monthly foliar fertilization (except in winter) were compared: A1 = NPK 14-7-28 + Mg (0.5 g/L); A2 = A1 + soluble humus $(75 \mathrm{mg} / \mathrm{L}) ; \mathrm{A} 3=$ soluble humus $(75 \mathrm{mg} / \mathrm{L}) ; \mathrm{A} 4$ = control without fertilizer application. The plants with the A1 treatment presented greater shoot growth and a bigger root system than the non-fertilized plants.

Keywords: Bromeliaceae, mineral nutrition, species conservation

\section{INTRODUÇÃO}

Tillandsia kautskyi E. Pereira (PEREIRA, 1974) é uma pequena bromélia epífita com folhas de cor cinza e inflorescências rosadas, nativa do Estado do Espírito Santo (ES), Brasil (figura 1). Está incluída na lista de espécies em risco de extinção, elaborada pela Convention on International Trade in Endangered Species of Wild Fauna and Flora (CITES, 2001). Pouco se conhece sobre métodos para o cultivo de T. kautskyi, considerado difícil por alguns colecionadores.

BENZING \& RENFROW (1980) chamaram as plantas do gênero Tillandsia de "bromélias atmosféricas”, porque absorvem água e nutrientes diretamente do ar, em vez de obtê-los do solo ou, como a maioria das bromélias epífitas, de material orgânico armazenado na parte central da planta, em uma concavidade formada pelas folhas ("tanque”), ausente nas tilândsias. Esses autores afirmaram que as raízes das bromélias atmosféricas são usadas somente para fixação da planta no substrato. A absorção de água e sais nas tilândsias, segundo BENZING et al. (1976), é feita por escamas peltadas, também chamadas de tricomas, que revestem as folhas de bromélias.

PAGANO \& SARTORI (1980) destacaram a importância da chuva e do orvalho como fornecedores de água e nutrientes a Tillandsia recurvata e T. pohliana. Pesquisando Tillandsia usneoides, PAGANO \& GONÇALVES (1982) sugeriram a existência de um mecanismo de translocação de nitrogênio dos tecidos senescentes para os tecidos mais jovens, como forma de conservação desse elemento.

De acordo com a Sociedade Brasileira de Bromélias (JARDIM DE FLORES, 2005), é preciso cuidado especial quando se aplicam fertilizantes em bromélias, pois elas são extremamente sensíveis a excesso de nutrientes e os absorvem com muita facilidade pelas folhas. Em decorrência de seu peculiar mecanismo de aquisição de nutrientes, as Tillandsia, possivelmente, são ainda mais sensíveis do que outras Bromeliaceae.

Considerando a necessidade de se estabelecer métodos de cultivo que contribuam para a conservação de T. kautskyi, este trabalho teve o objetivo de observar o efeito de duas fontes de nutrientes (mineral e orgânica) em aplicação foliar sobre o crescimento dessa espécie.

Foi hipótese de trabalho que poderiam ser obtidos resultados satisfatórios adaptando-se a adubação mineral recomendada para bromélias por SILVA \& COUTINHO (1999) e pela Sociedade Brasileira de Bromélias (JARDIM DE FLORES, 2005), e que a aplicação de húmus poderia ser benéfica, por ter influenciado positivamente o desenvolvimento de Aechmea fasciata Bak. (D'ANDRÉA \& DEMATTÊ, 2000).

\section{MATERIALEMÉTODOS}

O experimento foi conduzido em Jaboticabal, SP,

\footnotetext{
(1)Departamento de Produção Vegetal, Faculdade de Ciências Agrárias e Veterinárias, Unesp, Câmpus de Jaboticabal. Via de Acesso Prof. Paulo Donato Castellane, S/N., 14884-900, Jaboticabal (SP), Brasil. E-mail: inga.ambiental@netsite.com.br
} 
$21^{\circ} 15^{\prime}$ de latitude sul e $48^{\circ} 15^{\prime}$ de longitude oeste.

Os valores médios de temperatura e umidade relativa do ar em Jaboticabal, no período de 1971 a 2000, foram de $22,2^{\circ} \mathrm{Ce} 70,8 \%$, respectivamente, fevereiro e outubro foram os meses mais quentes (média de $20,6^{\circ} \mathrm{C}$ ), e julho, o mês mais frio (média de $12,5^{\circ} \mathrm{C}$ ); a média da precipitação total anual, no mesmo período, foi de 1.424,6 mm (UNESP, 2004). O fotoperíodo local varia das $10 \mathrm{~h} 50 \mathrm{~min}$ às $13 \mathrm{~h} 26 \mathrm{~min}$ (Prof. Dr. Clovis Alberto Volpe, comunicação pessoal). A altitude local é de, aproximadamente, 560 metros.

As plantas da espécie estudada, Tillandsia kautskyi E. Pereira, eram procedentes do Orquidário Binot, Petrópolis (RJ), e foram cultivadas no Viveiro Experimental de Plantas Ornamentais e Florestais, Câmpus de Jaboticabal da Universidade Estadual Paulista (Unesp), em casa de vegetação (telado) com 70\% de interceptação da luz solar, resultando em iluminância de 20.000 a 40.000 lux.

O experimento foi conduzido em delineamento de blocos casualizados, com oito repetições, e cada unidade experimental representada por um vaso com uma planta. As mudas foram distribuídas nos blocos de acordo com a semelhança de tamanho, pois o lote não era uniforme e não havia outras mudas disponíveis em quantidade suficiente.

Na ocasião do plantio, em 16-1-2003, a parte aérea das mudas tinha, em média, 4,5 cm de altura e 2,3 cm de diâmetro máximo, e a análise de variância não detectou diferenças significativas $(\mathrm{P}>0,05)$ dentro dos blocos. As raízes já existentes foram deixadas somente até $3 \mathrm{~cm}$ de comprimento, cortando-se a parte restante.

As mudas foram plantadas em vasos de plástico preto com 14,5 cm de diâmetro superior, $11,0 \mathrm{~cm}$ de diâmetro inferior e 11,0 cm de altura. Apesar de o cultivo em vasos não ser recomendado para tilândsias, especialmente as que apresentam folhas duras de cor cinza (PAULA \& SILVA, 2001; BROMELIAD SOCIETY INTERNATIONAL, 2005; JARDIM DE FLORES, 2005), esse foi o método que possibilitou a sobrevivência dessas plantas no Viveiro Experimental, pois elas não se adaptaram ao cultivo em placas fibrosas.

O substrato usado era constituído de $100 \%$ de fibra de coco (Golden Mix Fibroso ${ }^{\circledR}$, fabricado pela empresa Amafibra - Fibras e Substratos Agrícolas da Amazônia Ltda.). De acordo com informação dos fabricantes, tem valor de condutividade elétrica (CE), determinado em diluição de 2:1 (2 partes de água destilada para 1 parte de substrato), entre 0,2 e 0,4 mS/cm. Análises realizadas no laboratório do Departamento de Solos e Nutrição de Plantas da Escola Superior de Agricultura Luiz de Queiroz, Piracicaba (SP), determinaram os seguintes valores para propriedades físicas e químicas iniciais do substrato utilizado: $\mathrm{pH}$ em $\mathrm{CaCl}_{2}$ 0,01M com umidade natural: 4,0; densidade com umidade natural: $0,10 \mathrm{~g} / \mathrm{cm}^{3}$; umidade total: 15,44\%; matéria orgânica total (combustão) em base seca: 91,58\%; N: 0,60\%; $\mathrm{P}_{2} \mathrm{O}_{5}$ : 0,04\%; $\mathrm{K}_{2} \mathrm{O}: 1,30 \%$; Ca: 0,15\%; Mg: 0,13\%; S: 0,04\%; Cu: 13 mg/kg; Fe: 6.753 mg/kg; Mn: 48 mg/kg; Zn: 111 mg/kg; B: 33 mg/kg; Na: 497 $\mathrm{mg} / \mathrm{kg}$. Os macronutrientes e micronutrientes estão expressos em teores totais.

A primeira adubação foliar foi feita em 13-3-2003. Seguiram-se adubações mensais, exceto nos meses mais frios (junho, julho e agosto de 2003), em que não foram realizadas. A opção por adubações mensais, em vez de semanais, conforme recomenda a Sociedade Brasileira de Bromélias (JARDIM DE FLORES, 2005) para as diversas espécies de Bromeliaceae, foi motivada pela possível sensibilidade maior das plantas do gênero Tillandsia à aplicação de nutrientes.

Os tratamentos comparados foram os seguintes: A1 = aplicação, nas folhas, de adubo NPK 14-7-28 com adição de magnésio em forma de $\mathrm{MgO}$ (44\% de Mg), na proporção de $1 \mathrm{~g}$ por $\mathrm{kg}$ de adubo NPK (440 mg de Mg por kg de NPK), sendo a diluição da mistura de adubos de 0,5 g por litro de água; A2 = aplicação, nas folhas, de adubo $\mathrm{NPK}+\mathrm{Mg}$ em quantidade idêntica a do tratamento A1, misturando-se, na solução, húmus solúvel na dose de 75 mg por litro de água; A3 = aplicação nas folhas, de húmus solúvel na dose de 75 mg por litro de água; A4 = testemunha sem adubação.

O húmus solúvel usado foi o Humisolve-BR $\AA$, um extrato de ácidos húmicos e fúlvicos, contendo, aproximadamente, 25\% de ácidos húmicos e 12,5\% de ácidos fúlvicos. A dose aplicada foi a recomendada pela empresa distribuidora do produto. Segundo KONONOVA (1966), os principais componentes das substâncias húmicas são carbono (45 a 65\%), oxigênio (30 a 48\%), nitrogênio (2 a 6\%) e hidrogênio (abaixo de 5\%).

As plantas foram mantidas sob uma bancada do telado, para diminuir sua exposição ao sol. A irrigação foi fornecida por aspersão, a cada três dias. Não foram feitas adubações complementares.

O período experimental estendeu-se de janeiro de 2003 a maio de 2004. Foram feitas avaliações mensais do crescimento das plantas, considerando-se a altura e o diâmetro máximo da parte aérea. Em cada avaliação, as folhas secas foram contadas e retiradas. Qualquer alteração de aparência das plantas foi também registrada. No final do experimento, as plantas foram retiradas do substrato, anotando-se o número de raízes novas e o comprimento do sistema radicular.

\section{RESULTADOS E DISCUSSÃO}

As temperaturas máximas e mínimas mensais registradas no telado durante o período de cultivo, foram, respectivamente, de $42,5^{\circ} \mathrm{C}$ (setembro de 2003) e $5,5^{\circ} \mathrm{C}$ (agosto de 2003). A umidade relativa do ar foi sempre superior a $50 \%$.

Pouco tempo depois do plantio, em março de 2003, morreram duas plantas no tratamento A1 (nos blocos 1 e 2) e uma no tratamento A3 (no bloco 1). Por isso, os blocos 1 e 2 foram excluídos do experimento, restando, portanto, seis blocos, avaliados até o final.

A morte da primeira planta em A1 teve outra causa que não os tratamentos, pois ocorreu antes da primeira adubação. Sobre a morte das outras duas plantas no período inicial, em A1 e A3, é pouco provável que tenha sido causada pelos métodos de adubação referentes a esses tratamentos, pois, no tratamento A2, representado pela aplicação conjunta dos métodos A1 e A3, não houve mortalidade no início.

Durante o período experimental, nenhuma planta floresceu. $\mathrm{O}$ final do experimento foi determinado pela morte 
de três plantas nos blocos avaliados, duas no tratamento A4 (testemunha sem adubação) e uma no tratamento A2. Portanto, o número total de plantas mortas no experimento, considerando os blocos excluídos e os analisados, foi de seis. As plantas sobreviventes (21 nos blocos avaliados) mantiveram boa aparência.

Os valores máximos atingidos pelas variáveis avaliadas encontram-se na tabela 1. Esses valores, com exceção do diâmetro máximo da parte aérea, referem-se à avaliação final, em maio de 2004.

A altura da parte aérea foi a variável que melhor expressou diferenças de crescimento, indicando a superioridade do método de adubação A1 em relação ao A3 e à testemunha sem adubação (tabela 1). Esse crescimento deveu-se tanto ao alongamento dos órgãos já existentes quanto à formação de novas folhas. A figura 2 mostra as tendências de crescimento em altura durante o período experimental; as plantas sem adubação (A4) não chegaram a apresentar aumento significativo de altura ao longo do tempo.

As plantas de A1 foram as únicas que aumentaram o diâmetro durante o experimento (tabela 1), indicando, mais uma vez, que esse foi o melhor tratamento.

Com referência ao comprimento do sistema radicular, os valores de A1 foram significativamente maiores que os da testemunha (tabela 1). O efeito da adição de nutrientes sobre o crescimento radicular de Tillandsia kautskyi deve ser melhor pesquisado, pois remete à afirmação de BENZING \& RENFROW (1980) de que as raízes das tilândsias não atuam na absorção. No presente estudo, a aplicação de nutrientes foi feita nas folhas, mas, em outro experimento, DEMATTÊ (2005) constatou efeito de nutrientes do substrato sobre o crescimento de raízes de T. kautskyi; nesse caso, estaria ocorrendo absorção também pelas raízes.

O número de raízes novas e o número acumulado de folhas secas (referentes à última avaliação) indicaram tendência contrária. A análise de regressão linear entre essas variáveis e os dados de comprimento do sistema radicular resultou em valores de F significativos $(\mathrm{P}<0,01)$, respectivamente de $23,73^{* *}$ e $9,25^{* *}(\mathrm{r}=0,7204 * *$; $\mathrm{r}=$ $0,5441^{* *}$ ) para número de raízes e número acumulado de folhas secas. Assim, as plantas do tratamento A1 tenderam a desenvolver mais raízes e menos folhas secas do que as da testemunha. A perda de menos folhas por senescência indica maior resistência das plantas desse tratamento.

Considerando os bons resultados observados por D’ANDRÉA \& DEMATTÊ (2000) com a inclusão de húmus na adubação de Aechmea fasciata, esperava-se que o mesmo acontecesse com Tillandsia kautskyi, mas isso não ocorreu. A aplicação de húmus ou foi insuficiente para proporcionar crescimento maior que o das plantas não-adubadas, ou teve efeito adverso, pois sua aplicação conjunta com os adubos utilizados em A1 (combinação representada pelo tratamento A2) também não resultou em aumento de crescimento significativo em relação às plantas não-adubadas; ressalte-se que A1 (em que não havia húmus) produziu os melhores resultados. Essas constatações exemplificam as diferenças das espécies de bromélias em relação à exigência nutricional e indicam uma possível intolerância de T. kautskyi a componentes do húmus ou à concentração em que foi aplicado.

De acordo com LANDGRAF et al. (1999), a composição elementar das substâncias húmicas é variável e, por causa de sua natureza heterogênea e complexa, pouco se sabe sobre sua origem, síntese, estrutura química e funções, apesar dos vários estudos que envolvem tentativas de elucidação (KONONOVA, 1966; MALCOLM, 1990). Com relação a componentes que poderiam ter sido tóxicos às plantas, McKNIGHT et al. (1994) encontraram 0,45\% e $0,61 \%$ de cloro em ácidos fúlvicos de duas procedências. Outra possibilidade é a de que o húmus, quando aplicado juntamente com o adubo mineral, tenha resultado em fornecimento excessivo de nitrogênio.

Há ainda outros aspectos importantes a serem estudados, como é o caso de doses de potássio. Essa é uma observação feita com poucas plantas disponíveis, não foram incluídos tratamentos com variação das doses desse nutriente e, conseqüentemente, da relação entre as concentrações de $\mathrm{N}$ e K, cuja importância foi ressaltada por KÄMPF (1984) para o cultivo de Aechmea fasciata Bak. Em experimento de DEMATTÊ (2005), o sistema radicular de plantas de T. kautskyi desenvolveu-se melhor em substratos com teores mais altos de potássio (dentro dos limites de variação de 0,22 a 1,30 \%); o substrato que proporcionou os melhores resultados foi o utilizado no presente trabalho. Mesmo assim, é possível que doses maiores de potássio no fertilizante sejam benéficas. É preciso considerar que, embora as raízes não tenham interesse ornamental nas bromélias, há indícios (DEMATTÊ, 2005) de que elas são importantes para a sobrevivência de T. kautskyi.

A proporção de magnésio misturado ao adubo NPK também deve ser pesquisada, pois existe recomendação recente, para adubação de Tillandsia (BROMELIA, 2005), que indica quantidade maior (10\% de $\mathrm{MgSO}_{4}$, com $16 \%$ de $\mathrm{MgO}$ ) do que a empregada nesse estudo.

A maior limitação ao aprofundamento de pesquisas com T. kautskyi é a escassez de plantas. Por isso, antes de tudo, é necessário que se desenvolvam métodos eficientes visando à sua multiplicação por sementes.

\section{CONCLUSÃO}

Adubação foliar mensal, exceto nos meses de inverno, com adubo de fórmula NPK 14-7-28 + magnésio, na diluição de 0,5 g por litro de água, proporciona aumento da altura da parte aérea e do comprimento do sistema radicular de plantas de Tillandsia kautskyi.

\section{AGRADECIMENTOS}

A autora agradece ao Orquidário Binot, Petrópolis (RJ), pela doação das plantas utilizadas nesse estudo; à Dra. Maria das Graças Lapa Wanderley, do Instituto de Botânica do Estado de São Paulo, pela identificação da espécie; ao Engenheiro. Agrônomo. Orlando Graeff, da Sociedade Brasileira de Bromélias, pela ajuda na obtenção das plantas e por informações fundamentais à pesquisa; ao Senhor. Ângelo Luis Malvestiti, por informações sobre 
o substrato utilizado; ao Prof. Dr. José Carlos Barbosa, pelo auxílio nas análises estatísticas; ao CNPq, pelo apoio ao projeto.

\section{REFERÊNCIAS}

BENZING, D. H.; HENDERSON, K.; KESSEL, B.; SULAK, J. The absorptive capacities of bromeliad trichomes. American Journal of Botany, Columbus, v.63, n.7, p.10091014, 1976

BENZING, D. H.; RENFROW, A. The nutritional dynamics of Tillandsia circinnata in Southern Florida and the origin of the "air plant” strategy. Botanical Gazette, Chicago, v.141, n.2, p.165-172, 1980.

BROMELIA. Instructions for growing bromeliads. Disponível em: <http://www.bromelia.com/cultuur.html\#4>. Acesso em: 26 mai.2005.

BROMELIAD SOCIETY INTERNATIONAL. Bromeliad info. Disponível em: <http://bsi.org/>. Acesso em: 17 fev.2005.

CITES. Convention on International Trade in Endangered Species of Wild Fauna and Flora. Disponível em: $<\underline{\text { http: } / /}$ www.cites.org/eng/disc/what is.shtml>. Acesso em: 8 ago.2001.

D’ANDRÉA, J. C.; DEMATTÊ, M. E. S. P. Effect of growing media and fertilizers on the early growth of Aechmea fasciata Bak. Acta Horticulturae, Leuven, v.511, p.271276, 2000.

JARDIM DE FLORES. Bromélias. Disponível em: http:// www.jardimdeflores.com.br/floresefolhas/ A11bromelia.htm. Acesso em: 13 fev.2005.

DEMATTÊ, M. E. S. P. Cultivo de Tillandsia kautskyi E. Pereira, bromélia brasileira em risco de extinção: comparação de substratos. Revista Brasileira de Horticultura
Ornamental, Campinas, v.11, n.2, p.114-120, 2005.

KÄMPF, A. N. Aspectos da nutrição de bromeliáceas epífitas. In: CONGRESSO BRASILEIRO DE FLORICULTURAE PLANTAS ORNAMENTAIS, 4., 1983, Rio de Janeiro. Anais... Brasília: Embrapa, 1984. p.187-198.

KONONOVA, M. M. Soil organic matter: its nature, its role in soil formation and in soil fertility. 2.ed. New York: Pergamon, 1966. p.544.

MALCOLM, R. L. The uniqueness of humic substances in each of soil, stream and marine environments. Analytica Chimica Acta, Amsterdam, v.232, p.19-30, 1990.

McKNIGHT, D. M.; ANDREWS, E. D.; SPAULDING S. A.; AIKEN, G. R. Aquatic fulvic acids in algae-rich antartic ponds. Limnology and Oceanography, Baltimore, v.39, n.8, p.1972-1979, 1994.

PAGANO, S. N.; GONÇALVES, M. B. Variação sazonal dos teores de N, P, K, Ca e Na em Tillandsia usneoides Linn. Naturalia, São Paulo, v.7, p.93-97, 1982.

PAGANO, S. N.; SARTORI, A. A. Variação anual de NPK em folhas de duas Bromeliaceae epífitas. Revista Brasileira de Biologia, Rio de Janeiro, v.40, n.1, p.25-29, 1980.

PAULA, C. C. de; SILVA, H. M. P. da. Cultivo prático de bromélias. 2.ed. Viçosa: UFV, 2001. 73p.

PEREIRA, E. Species novae in Brasilia Bromeliacearum VII. Bradea, Rio de Janeiro, v.1, p.437-439, 1974.

SILVA, M. C.; COUTINHO, C. E. A beleza exótica das orquídeas e bromélias de Roberto A. Kautsky. Vitória: M\&M Publicidade e Promoções, 1999. p.116-117.

UNESP. Câmpus de Jaboticabal. Estação Agroclimatológica. Valores médios do período 1971-2000. Disponível em < http://www.fcav.unesp.br/Departamentos/ exatas/estacao/normal.htm>. Acesso em: 30 abr.2004.

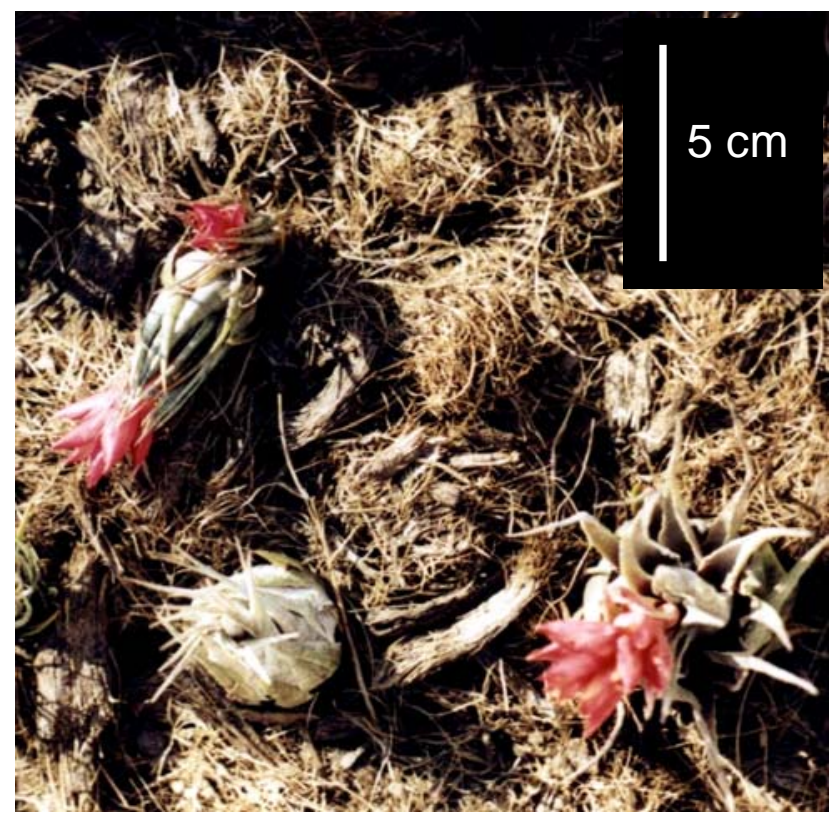

Figura 1. Tillandsia kautskyi E. Pereira. (Foto de M. E. S. P. Demattê). 


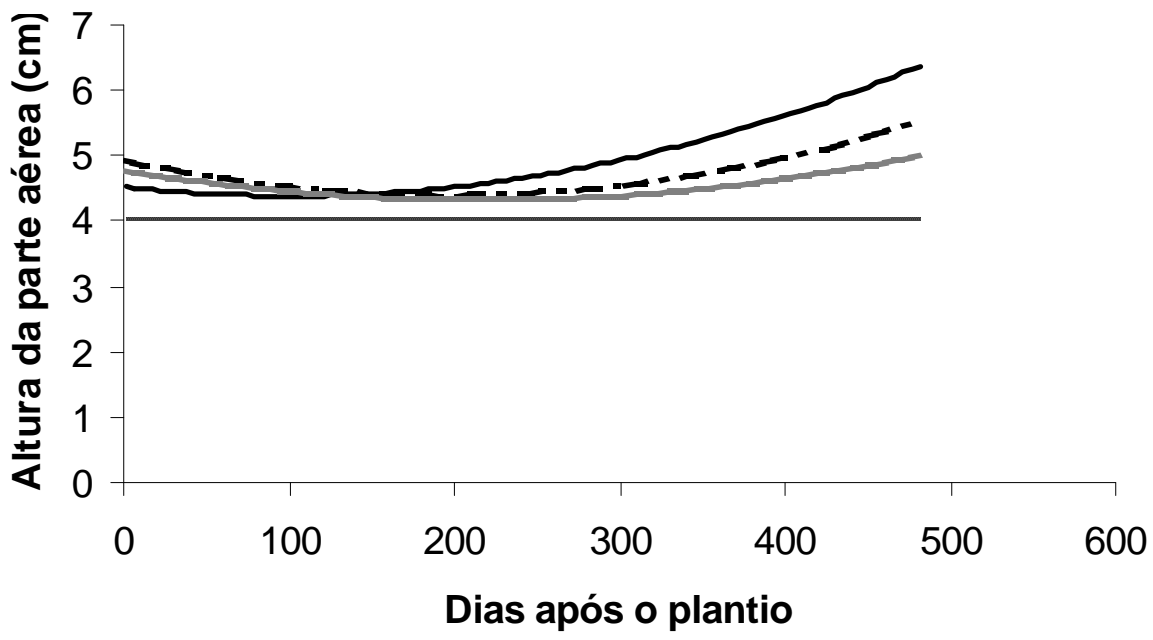

Figura 2. Linhas de tendência de altura da parte aérea de plantas de Tillandsia kautskyi E. Pereira em função do tempo de cultivo com diferentes métodos de adubação foliar mensal.

A1 = adubo NPK 14-7-28 + Mg (0,5g/L); A2 = A1 + húmus solúvel (75 mg/L); A3 = húmus solúvel (75 mg/L); A4 = testemunha sem adubação.

Equações ajustadas e valores de $\mathrm{R}^{2}$ :

para A1, $y=1 E-0,5 x^{2}-0,0027 x+4,5257 ; R^{2}=0,8226$;

para A2, $y=1 E-0,5 x^{2}-0,0053 x+4,9272 ; R^{2}=0,8111$;

para $A 3, y=1 E-0,5 x^{2}-0,0042 x+4,7773 ; R^{2}=0,2781$;

para A4, não houve ajuste de equação.

Tabela 1. Médias dos valores máximos atingidos por variáveis de desenvolvimento de plantas de Tillandsia kautskyi E. Pereira registradas durante o período de cultivo com diferentes métodos de adubação (janeiro de 2003 a maio de 2004)

\begin{tabular}{ccccccc}
\hline Adubação(1) $^{(1)}$ & $\begin{array}{c}\text { Número } \\
\text { acumulado } \\
\text { de folhas } \\
\text { secas }^{(2)}\end{array}$ & $\begin{array}{c}\text { Altura da } \\
\text { parte aérea } \\
(\mathrm{cm})\end{array}$ & $\begin{array}{c}\text { Diâmetro } \\
\text { máximo da } \\
\text { parte aérea } \\
(\mathrm{cm})^{(3)}\end{array}$ & $\begin{array}{c}\text { Número de } \\
\text { brotos }^{(2)}\end{array}$ & $\begin{array}{c}\text { Número de } \\
\text { raízes } \\
\text { novas de } \\
\text { primeira } \\
\text { ordem }^{(2,4)}\end{array}$ & $\begin{array}{c}\text { Comprimento } \\
\text { máximo do } \\
\text { sistema } \\
\text { radicular } \\
(\mathrm{cm})^{(2)}\end{array}$ \\
\hline A1 & 12,0 & $6,5 \mathrm{a}$ & 5,2 & 0,0 & 4,8 & $2,4 \mathrm{a}$ \\
A2 & 16,7 & $5,6 \mathrm{ab}$ & 4,8 & 0,3 & 4,8 & $2,1 \mathrm{ab}$ \\
A3 & 12,8 & $4,6 \mathrm{~b}$ & 4,3 & 1,2 & 3,3 & $1,5 \mathrm{ab}$ \\
A4 & 22,7 & $4,5 \mathrm{~b}$ & 4,1 & 0,7 & 1,8 & $1,3 \mathrm{~b}$ \\
F & $2,08 \mathrm{~ns}$ & $5,94 * *$ & - & $1,57 \mathrm{~ns}$ & $2,25 \mathrm{~ns}$ & $4,74 *$ \\
$\mathrm{CV}(\%)$ & 24,16 & 18,00 & - & 42,16 & 36,42 & 31,52 \\
\hline
\end{tabular}

(1) A1 = adubo NPK 14-7-28 + Mg (0,5 g/L); A2 = A1 + húmus solúvel (75 mg/L); A3 = húmus solúvel (75 mg/L); A4 = testemunha sem adubação.

(2) Nesta tabela, são apresentados os dados originais; as análises foram feitas com dados transformados $(\sqrt{x}$ para número

acumulado de folhas secas; $\sqrt{x+0,5}$ para número de inflorescências, número de brotos, número de raízes novas de primeira

ordem e comprimento máximo do sistema radicular).

(3) Sem análise estatística.

(4) Raízes que dão origem às ramificações.

ns = não-significativo; * = significativo a $5 \%$ de probabilidade; $* *=$ significativo a $1 \%$ de probabilidade.

Médias seguidas por letras distintas, na coluna, diferem entre si, a 5\% de probabilidade, pelo teste de Tukey.

$\mathrm{CV}=$ Coeficiente de Variação. 